\title{
Development of a Partition-Controlled Dosing System for Cell Assays
}

\author{
Nynke I. Kramer, ${ }^{*}{ }^{\dagger}$ Frans J. M. Busser, ${ }^{\dagger}$ Mattheus T. T. Oosterwijk, ${ }^{\dagger}$ Kristin Schirmer ${ }^{\ddagger}{ }^{\ddagger}$ \\ Beate I. Escher, ${ }^{\ddagger, l l}$ and Joop L. M. Hermens \\ Institute for Risk Assessment Sciences, Utrecht University, P.O. Box 80177, 3508 TD Utrecht, The Netherlands, \\ Eawag, Swiss Federal Institute of Aquatic Science and Technology, Überlandstrasse 133, P.O. Box 611, \\ 8600 Dübendorf, Switzerland, ETH Zürich, Institute of Biogeochemistry and Pollutant Dynamics, CHN G50.3, \\ Universitätstrasse 16, 8092 Zürich, Switzerland, and The University of Queensland, National Research Centre \\ for Environmental Toxicology (Entox), 39 Kessels Road, Coopers Plain QLD 4108, Australia
}

Received August 1, 2010

\begin{abstract}
Hydrophobic and volatile chemicals have proven to be difficult to dose in cell assays. Cosolvents are often needed to dissolve these chemicals in cell culture medium. Moreover, the free concentration of these chemicals in culture medium may diminish over time due to metabolism, evaporation, and nonspecific binding to well plate surfaces and serum constituents. The aim of this study was to develop a partitioncontrolled dosing system to maintain constant concentrations of benzo(a)pyrene, 1,2-dichlorobenzene, and 1,2,4-trichlorobenzene in an ethoxyresorufin- $O$-deethylase (EROD) assay and a cytotoxicity assay with the rainbow trout (Oncorhynchus mykiss) cell lines RTL-W1 and RTgill-W1. Polydimethylsiloxane (PDMS) sheets were loaded with test chemicals in a spiked methanol/water solution and placed in the wells, filled with culture medium, of a 24-well culture plate. Cells were grown on inserts and were subsequently added to the wells with the PDMS sheets. The system reached equilibrium within $24 \mathrm{~h}$, even for the very hydrophobic chemical benzo $(a)$ pyrene. The reservoir of test chemical in PDMS was large enough to compensate for the loss of $>95 \%$ of the test chemical from the culture medium. The PDMS sheets maintained medium concentrations constant for $>72 \mathrm{~h}$. Nominal median effect concentrations $\left(\mathrm{EC}_{50}\right)$ were 1.3-7.0 times lower in the partition-controlled dosing systems than in conventional assays spiked using dimethyl sulfoxide (DMSO) as a carrier solvent, thus indicating that the apparent sensitivity of the bioassay increased when controlled and constant exposure conditions could be assured. The $\mathrm{EC}_{50}$ values of the test chemicals based on free concentrations were estimated in the partition-controlled dosing systems using measured PDMS-bare culture medium partition coefficients. Results indicated that 61, 70, and $99.8 \%$ of 1,2-diclorobenzene, 1,2,4-trichlorobenzene, and benzo(a)pyrene were bound to serum constituents in the culture medium.
\end{abstract}

\section{Introduction}

In vitro cell assays are considered a promising alternative to fish bioassays in toxicological testing. Cells in microtiter plates can be exposed to a large number of test chemicals and analyzed in high throughput systems. Few, if any, animals are used, little test substance is needed, and little toxic waste is produced. Furthermore, in vitro studies can address aspects of toxic mechanisms underlying a general toxic response $(1,2)$. Indeed, good correlations have been found between in vitro derived median effect concentrations $\left(\mathrm{EC}_{50}{ }^{1}\right)$ and median acutely lethal concentrations in fish $\left(\mathrm{LC}_{50}\right)$. However, there is room for

\footnotetext{
* Corresponding author. Tel: +3130253 5314. Fax: +31 302535077. E-mail: N.I.Kramer@uu.nl.

$\dagger$ Utrecht University.

$\div$ Swiss Federal Institute of Aquatic Science and Technology.

§ Institute of Biogeochemistry and Pollutant Dynamics.

"The University of Queensland.

${ }^{1}$ Abbreviations: CFDA-AM, 5-carboxyfluorescein diacetate, acetoxymethyl ester; DMEM, Dulbecco's modified Eagle's medium; DMSO, dimethyl sulfoxide; $\mathrm{EC}_{50}$, median effect concentration; $\mathrm{ECD}$, electron capture detector; EROD, ethoxyresorufin- $O$-deethylase; FBS, fetal bovine serum; $K_{\mathrm{OW}}$, octanol-water partition coefficient; $\mathrm{LC}_{50}$, median lethal concentration; n/a, not applicable; NRU, Neutral Red uptake; OECD, Organisation for Economic Co-operation and Development; PAH, polycyclic aromatic hydrocarbon; PBS, phosphate buffered saline; PDMS, polydimethylsiloxane; RTgill-W1, rainbow trout gill cell line; RTL-W1, rainbow trout liver cell line; SPMD, semipermeable membrane devices.
}

improvement when considering the apparent low sensitivity of in vitro derived toxicity data (3). For a range of industrial organic chemicals, in vitro $\mathrm{EC}_{50}$ values were on average an order of magnitude higher than $\mathrm{LC}_{50}$ values in fish. Moreover, it was also found that the differences between observed toxicity in in vitro and in vivo systems were more pronounced for hydrophobic and volatile chemicals (4).

Indeed, hydrophobic and volatile chemicals have proven to be difficult to dose and obtain reliable results for in cell-based assays (5). One possible reason for this is that the free concentration of a test chemical can be much lower than the nominal concentration and can vary considerably between assays and over time. Traditionally, the effect concentration obtained from a cell assay is based on the nominal concentration of a test chemical added to the culture medium at the start of the exposure period. However, studies have found volatile chemicals to significantly evaporate from microtiter plates, resulting in higher effect concentrations observed in microtiter plates than in sealed flasks $(6,7)$. Studies have also found that serum protein in culture medium, microtiter plate plastic, and cell lipids significantly bind and reduce the free concentration of hydrophobic test chemicals in cell assays $(8-14)$. Changes in cell assay setup, such as changes in serum levels and cell concentrations, may therefore alter the observed nominal effect concentration $(10-14)$. Moreover, cosolvents are normally used to dose 
poorly soluble test chemicals in cell assays. These cosolvents may interact with the test chemical and interfere with the biological activity of assay systems $(5,15-17)$.

Therefore, the establishment of a solvent-free dosing system compensating for the loss of test chemicals in cell assays over time is a welcome development. Such a system would have to satisfy a number of criteria $(18,19)$. It must ensure that the chemical is truly dissolved, it must maintain stable and predictable concentrations over the test period, it must compensate fully and quickly for losses of the chemical from the exposure medium, and it must not interfere with the biological activity. To meet these criteria, fish bioassays use flow-through systems $(20,21)$. However, these are poorly amenable to cell assays due to the sensitive nature of cells to flows and the miniaturized setup. Instead, partition-controlled dosing systems may be used $(18,22)$. Here, a solid phase is loaded with a test chemical and introduced into the exposure medium. The chemical partitions between the solid phase and the medium. In so doing, the resulting concentration of the chemical in the exposure medium remains below solubility. Losses are compensated for by the release of the chemical from the solid phase in order to maintain the chemical equilibrium between the solid phase and the medium.

A number of studies have used a variation of the partitioncontrolled dosing system in bioassays, each with their advantages and disadvantages. Janz and Schacter (23) successfully loaded $\beta$-cyclodextrins with isoalkanes to dose human lymphoma cell cultures. However, it may be difficult to apply the method to other chemicals. The range of chemicals with a specific affinity for a particular cyclodextrin species is limited. Bopp et al. (24) successfully loaded microtiter plate plastic and plastic beads with polycyclic aromatic hydrocarbons (PAHs) to dose RTL-W1 cells in an ethoxyresorufin- $O$-deethylase (EROD) assay. Here, however, the determination of the exact concentration to which the cells are exposed is difficult to determine as cells are in direct contact with the dosing material. Heinis et al. (25) used semipermeable membrane devices (SPMDs) to dose PAHs in static fish and invertebrates acute toxicity tests. Mayer et al. (22) used Empore disks to dose tribromobenzene and hexachlorobenzene in an algae test system. The large size of both SPMDs and Empore disks limit their use in cell assays. Smith et al. (26) used silicone O-rings to dose PAHs in a cytokine promotor assay with human cells. However, the cells are not all equidistant from the dosing source and thus not equally exposed. Gerofke et al. (19) and Bandow et al. $(27,28)$ used Teflon coated stirrer bars and silicon rods to simultaneously stir and dose algae toxicity assays. However, many cells may not be amenable to these stirring regimes. PDMS films were used by Brown et al. (18) and Kiparissis et al. (29) in a Microtox bacterial toxicity test and a fish embryo toxicity test, respectively. However, considerable skill is required to apply and evenly load the film, and this dosing system is not applicable to assays with adherent cell cultures.

The aim of this study was to overcome some of the disadvantages associated with previously reported partitioncontrolled dosing systems and develop a partition-controlled dosing system that maintains constant concentrations of hydrophobic PAHs and volatile chlorobenzenes in an EROD assay and a cytotoxicity assay with fish cell lines. This study opted for using the loading and dosing techniques described in Kwon et al. (30). PDMS sheets of $1 \mathrm{~mm}$ thick were cut into $15 \mathrm{~mm}$ diameter disks, loaded in a methanol/water solution containing the test chemical, and introduced into a 24-well plate with the exposure medium. RTL-W1 and RTgill-W1 were separately grown on the bottom of the membrane of well plate inserts. The inserts were then added to the exposure medium to uniformly expose the cells to the test chemical without touching the PDMS surface. The kinetics of the partitioning, the range, stability and predictability of unbound (free) concentrations of the chemical in the exposure medium, and the reservoir potential of the PDMS sheets were first investigated. This was followed by a comparison of EROD activity, a catalytic measurement of cytochrome P450 1A induction, and cytotoxicity results from PDMS-based assays and from assays where the culture medium is spiked with the chemical (referred to as conventionally dosed cell assays).

\section{Materials and Methods}

Chemicals and Solvents. Benzo(a)pyrene and 1,2,4-trichlorobenzene were purchased from Sigma-Aldrich Chemie (Zwijndrecht, The Netherlands). 1,2-Dichlorobenzene was purchased from Fluka (Buchs, Switzerland). Acetonitrile, acetone, methanol, $n$ hexane, and cyclohexane were purchased from Labscan (Dublin, Ireland). Dimethyl sulfoxide (DMSO) was purchased from Fluka (Buchs, Switzerland), ethanol (absolute) from Sigma Aldrich (Zwijndrecht, The Netherlands), and glacial acetic acid from Merck (Amsterdam, The Netherlands). All test chemicals and solvents were of analytical grade $(>98 \%)$. Pure deionized water was prepared using a Millipore water purification system equipped with an organic-free kit (Millipore Waters, Amsterdam, The Netherlands). All cell culture media and buffers were purchased from Gibco BRL (Breda, The Netherlands). Polydimethylsiloxane (PDMS) sheets (1 $\mathrm{mm}$ thick, density of $1170 \mathrm{~kg} \mathrm{~m}^{-3}$, Specialty Silicone Products, Inc., Ballston, Spa, NY, USA) were cut into $15 \mathrm{~mm}$ diameter disks, cleaned in a Soxhlet extractor using $n$-hexane, followed by methanol for $3 \mathrm{~h}$ each, and stored in methanol until use.

Setup of the Partition-Controlled Dosing System. Cleaned 15 $\mathrm{mm}$ diameter PDMS disks were weighed and loaded in a 60/40\% (v/v) methanol/water loading-solution (1\% v/v PDMS/loadingsolution), which contained the chemicals separately. The disks were loaded for $72 \mathrm{~h}$ on a two-dimensional shaker at $190 \mathrm{rpm}$ (KS501, IKA Labortechnik, Staufen, Germany). Results from pilot experiments indicated that $72 \mathrm{~h}$ was enough time for the system to reach equilibrium. At equilibrium and assuming $100 \%$ mass balance, the concentration of individual test chemicals in PDMS $\left(C_{\mathrm{PDMS}}\right)$ was given by:

$$
C_{\mathrm{PDMS}}=\frac{C_{\text {loading-solution }}(t=0)}{\frac{1}{K_{\mathrm{PDMS} / \text { loading-solution }}}+\frac{V_{\mathrm{PDMS}}}{V_{\text {loading-solution }}}}
$$

where $K_{\text {PDMS/loading-solution }}$ is the partition coefficient of the test chemical between PDMS and the loading-solution, $C_{\text {loading-solution }}$ $(t=0)$ is the initial concentration of test chemical in the loadingsolution, and $V_{\text {PDMS }}$ and $V_{\text {loading-solution }}$ are the volumes of PDMS and loading-solution, respectively.

After loading, the PDMS disks were quickly dabbed dry on a tissue and placed on the bottom of each well in a 24-well tissueculture treated polystyrene microtiter plate (CELLSTAR, Greiner Bio-one, Alphen a/d Rijn, The Netherlands) under sterile conditions. Then, 1.7 mL Leibovitz's L-15 medium supplemented with $5 \%$ fetal bovine calf serum (FBS), $100 \mathrm{U} / \mathrm{L}$ penicillin, and $100 \mu \mathrm{g} / \mathrm{L}$ streptomycin was added to each well. Custom-made $1.5 \mathrm{~mm}$ thick plexiglass spacers were added to lift up the 24-well ThinCert inserts $\left(0.4 \mu \mathrm{m}\right.$ pore size, $2 \times 10^{6} \mathrm{~cm}^{-2}$ pore density, transparent PET membranes, Greiner Bio-one, Alphen a/d Rijn, The Netherlands), on which cells were grown (see Cell Culture and Assays section). The cells, therefore, did not touch the PDMS. A plate sealer (Microseal B Adhesive Seals, Bio-Rad, Veenendaal, The Netherlands) was placed on top of the spacer with inserts. The plate lid was placed on top of the sealer. The plate was wrapped in 


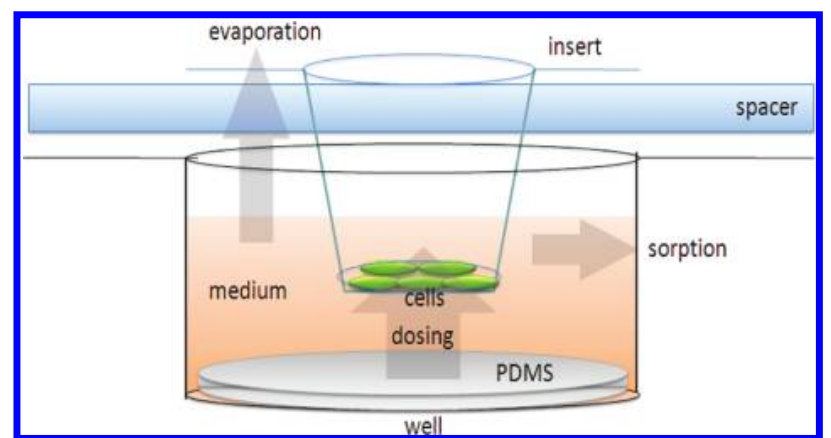

Figure 1. Schematic representation of the partition-controlled dosing system for fish cell assays. The arrows indicate the flow of the test chemical in the system. The cells were grown on the bottom of the insert membrane. This allowed the cells to be in direct contact with the bulk medium.

parafilm (Chiney Plastic Packaging Company, Chicago, IL) and incubated in the dark at $20^{\circ} \mathrm{C}$. A schematic of the setup is shown in Figure 1.

Kinetics and Free Medium Concentrations in the PartitionControlled Dosing System. To determine the kinetics of the dosing system, the PDMS disks were loaded with either $18.60 \mathrm{mg} / \mathrm{L}$ benzo(a)pyrene, $8.67 \mathrm{~g} / \mathrm{L}$ 1,2-dichlorobenzene, or $7.73 \mathrm{~g} / \mathrm{L} \mathrm{1,2,4-}$ trichlorobenzene in the loading-solution. All these concentrations were close to the maximum soluble concentrations in the methanol/ water loading-solution. The PDMS disks were then exposed in triplicate to the medium with and without 5\% FBS and RTgill-W1 cells for $0,1,2,4,8,24,48$, and $96 \mathrm{~h}$. The PDMS disks were subsequently dabbed dry on a tissue and shaken in $20 \mathrm{~mL}$ of acetonitrile (for PDMS disks loaded with benzo(a)pyrene) or 20 $\mathrm{mL}$ of cyclohexane (for PDMS disks loaded with chlorobenzenes) on a Stuart roller mixer (SRT9D, Warrenville, IL) at $60 \mathrm{rpm}$ for $48 \mathrm{~h}$. Subsequent extractions with the solvents showed that this technique extracted $>98 \%$ of the test chemical. Benzo( $a$ )pyrene in the medium was prepared for chemical analysis by mixing aliquots of medium with $10-20 \times(\mathrm{v} / \mathrm{v})$ acetonitrile and centrifuging at $10,000 \mathrm{rpm}, 4{ }^{\circ} \mathrm{C}$, for $10 \mathrm{~min}$ to precipitate the proteins (Sigma 1-14 Microcentrifuge, Satorius-Stedim, Nieuwegein, The Netherlands). Chlorobenzenes were extracted from the medium by adding $10-20 \times(\mathrm{v} / \mathrm{v})$ cyclohexane to aliquots of the medium. PDMS and medium extracts were then transferred to $1.8 \mathrm{~mL}$ autosampler vials and stored at $-20{ }^{\circ} \mathrm{C}$ until chemical analysis.

The total concentration of the test chemical in culture medium containing serum $\left(C_{\mathrm{L} 15 \text { serum }}\right)$ and in PDMS $\left(C_{\mathrm{PDMS}}\right)$ at time $t$ is given by:

$$
\begin{gathered}
C_{\mathrm{L} 15 \text { serum }}(t)=\frac{C_{\mathrm{PDMS}}(t=0) \cdot \frac{V_{\mathrm{PDMS}}}{V_{\mathrm{L} 15 \mathrm{serum}}}}{1+K_{\mathrm{PDMS} / \mathrm{L} 15 \text { serum }} \cdot \frac{V_{\mathrm{PDMS}}}{V_{\mathrm{L} 15 \text { serum }}}} \cdot \\
{\left[1-\exp \left(-\left(K_{\mathrm{PDMS} / \mathrm{L} 15 \text { serum }} \cdot \frac{V_{\mathrm{PDMS}}}{V_{\mathrm{L} 15 \text { serum }}}+1\right)\right) \cdot k_{d} \cdot t\right]}
\end{gathered}
$$

and

$$
\begin{aligned}
& C_{\mathrm{PDMS}}(t)= \frac{C_{\mathrm{PDMS}}(t=0)}{1+K_{\mathrm{PDMS} / \mathrm{L} 15 \mathrm{serum}} \cdot \frac{V_{\mathrm{PDMS}}}{V_{\mathrm{L} 15 \mathrm{serum}}}} \cdot \\
& {\left[K_{\mathrm{PDMS} / \mathrm{L} 15 \mathrm{serum}} \cdot \frac{V_{\mathrm{PDMS}}}{V_{\mathrm{L} 15 \mathrm{serum}}}+\right.} \\
&\left.\exp \left(-\left(K_{\mathrm{PDMS} / \mathrm{L} 15 \mathrm{serum}} \cdot \frac{V_{\mathrm{PDMS}}}{V_{\mathrm{L} 15 \text { serum }}}+1\right)\right) \cdot k_{d} \cdot t\right]
\end{aligned}
$$

where $K_{\mathrm{PDMS} / \mathrm{K} 15 \text { serum }}$ is the partition coefficient of the test chemical between PDMS and medium containing serum, and $C_{\mathrm{PDMS}}(t=0)$ is the initial concentration of the test chemical in PDMS (30). Assuming the chemical only partitions between PDMS and medium, $k_{\mathrm{d}}$ is the desorption rate constant in $\mathrm{s}^{-1}$. $V_{\mathrm{PDMS}}$ and $V_{\mathrm{L} 15 \mathrm{~s} e r u m}$ are the volumes of PDMS and medium, respectively. At equilibrium, the concentration of test chemical in the medium, $C_{\mathrm{L} 15 \mathrm{serum}(\mathrm{eq})}$, is a function of $K_{\mathrm{PDMS} / \mathrm{L} 15 \mathrm{serum}}, C_{\mathrm{PDMS}}(t=0)$, and the amount lost via evaporation, plastic binding, cell partitioning, and metabolism $\left(T_{\text {lost }}\right)$ :

$$
C_{\mathrm{L} 15 \text { serum(eq) }}=\frac{C_{\mathrm{PDMS}}(t=0)-\frac{T_{\text {lost }}}{V_{\mathrm{PDMS}}}}{K_{\mathrm{PDMS} / \mathrm{L} 15 \text { serum }}+\frac{V_{\mathrm{L} 15 \text { serum }}}{V_{\mathrm{PDMS}}}}
$$

For the partition-controlled dosing system to maintain a constant and predictable medium concentration, the amount of test chemical in the medium and the amount that is lost should be negligible compared to the amount in PDMS. If we assume this negligible loss and no saturation of constituents in the medium that bind the test chemical, eq 4 reduces to

$$
C_{\mathrm{L} 15 \text { serum(eq) }}=\frac{C_{\mathrm{PDMS}}(t=0)}{K_{\mathrm{PDMS} / \mathrm{L} 15 \text { serum }}}
$$

The free (unbound) concentration in the medium is approximated by the quotient of the initial concentration in PDMS and the partition coefficient between PDMS and serum-free culture medium $\left(K_{\mathrm{PDMS} / \mathrm{L} 15}\right)$ as follows:

$$
C_{\text {free }}=\frac{C_{\mathrm{PDMS}}(t=0)}{K_{\mathrm{PDMS} / \mathrm{L} 15}}
$$

Exposing Cells to Test Chemicals. The information obtained from the aforementioned kinetics experiments (e.g., $K_{\text {PDMS/L15serum }}$ ) was subsequently used to load PDMS disks with varying concentrations of benzo( $a$ )pyrene (0.08-306.63 mg/L PDMS), 1,2-dichlorobenzene (0.66-8.67 g/L PDMS), and 1,2,4-trichlorobenzene (2.40-264.93 $\mathrm{mg} / \mathrm{L}$ PDMS). Equations 1, 5, and 6 suggest that the initial concentration of the test chemical in the loading-solution is directly proportional, by means of a partition coefficient $K$, to the concentration in PDMS and in culture medium at equilibrium. Thus, by loading PDMS sheets in loading-solutions spiked with varying concentrations of test chemicals, the concentration of the test chemical in culture medium was varied. The disks loaded with chlorobenzenes were then used to dose RTgill-W1 cells in 5\% FBS medium in a basal cytotoxicity assay. PDMS disks loaded with benzo(a)pyrene were used to dose RTL-W1 cells in an EROD assay. For each assay, the PDMS disks were preincubated with the medium in the well plate for $24 \mathrm{~h}$ before cells were added. The cells were exposed for $48 \mathrm{~h}$ with 7 concentrations of the test chemical, three wells per concentration. Three negative controls (blank PDMS) were also included. Each assay, in turn, was performed thrice. Moreover, three loaded, but unexposed to medium, PDMS disks (for each concentration and assay) were extracted and analyzed to determine the initial test chemical concentration in PDMS. Exposed PDMS disks and medium were also extracted and analyzed.

Cytotoxicity and EROD assays were additionally performed using conventional dosing, simultaneously with the PDMS-dosed assays. The same medium concentration ranges of test chemicals were used as in the PDMS-dosed assays. Two-hundred times concentrated stock solutions of each test chemical were prepared in DMSO and used to spike the culture medium ( $0.5 \% \mathrm{v} / \mathrm{v} \mathrm{DMSO} /$ medium). The spiked medium was subsequently added to each well of a 24-well plate in a setup similar to that described above. The medium was extracted before and after exposure to the cells to analytically determine initial and exposed medium concentrations, respectively.

Cell Culture and Assays. The rainbow trout gill cell line, RTgillW1, was purchased from American Type Culture Collection (CCL- 
163, Manassas, VA). The cytochrome P450 1A-expressing rainbow trout liver cell line, RTL-W1, originated from Lee et al. (31). The cells were cultured in Leibovitz's L-15 culture medium supplemented with $100 \mathrm{U} / \mathrm{L}$ penicillin, $100 \mu \mathrm{g} / \mathrm{L}$ streptomycin, and $10 \%$ fetal calf serum (FBS). FBS contains $40 \mathrm{mg} / \mathrm{mL}$ bovine serum albumin, the main binding protein in serum (32) (as communicated by the supplier). Cells were incubated in closed $75 \mathrm{~cm}^{2}$ culture flasks at $20{ }^{\circ} \mathrm{C}$, as described in Ganassin et al. (33).

Experiments were performed on RTgill-W1 and RTL-W1 at passages of 10 to 30 and 90 to 110 , respectively. Cells were seeded at a density of 90,000 cells/insert in $100 \mu \mathrm{L}$ of culture medium on the bottom of 24-well inserts turned upside down in 12-well plates (Greiner Bio-one, Alphen a/d Rijn, The Netherlands). After $24 \mathrm{~h}$ of incubation at $20{ }^{\circ} \mathrm{C}$, the inserts were turned right sides up and transferred to 24-well plates with $1 \mathrm{~mL} /$ well culture medium and incubated for another $24 \mathrm{~h}$ at $20{ }^{\circ} \mathrm{C}$. The inserts with cells were then transferred to the 24-well plates containing the PDMS disks or the conventionally dosed culture medium $(1500 \mu \mathrm{L}$ in the well and $200 \mu \mathrm{L}$ in the insert). The cells were exposed for $48 \mathrm{~h}$ in the dark at $20{ }^{\circ} \mathrm{C}$.

After exposure to 1,2-dichlorobenzene and 1,2,4-trichlorobenzene, the Alamar Blue, CFDA-AM (5-carboxyfluorescein diacetate, acetoxymethyl ester), and Neutral Red uptake (NRU) assay were performed on the RTgill-W1 cells to assess metabolic activity, cell membrane integrity, and lysosomal membrane integrity, respectively. The assay procedures were adapted from Ganassin et al. (33) and Schirmer et al. (34). Briefly, after a washing step with phosphate buffered saline solution (PBS), the cells were incubated for $30 \mathrm{~min}$ in $400 \mu \mathrm{L}$ of $5 \%$ (v/v) Alamar Blue (Invitrogen, Breda, The Netherlands) and $4 \mu \mathrm{M}$ CFDA-AM (Invitrogen, Breda, The Netherlands) in PBS on a separate microtiter plate $(400 \mu \mathrm{L}$ was enough to fully submerge the cells on the bottom of the insert membrane). Alamar Blue and CFDA-AM fluorescence were, respectively, read at 530/595 $\mathrm{nm}$ and 493/541 nm using Tecan M200 (Tecan Group, Ltd., Männedorf, Switzerland). The cells were subsequently washed with PBS, incubated for $1 \mathrm{~h}$ in $400 \mu \mathrm{L}$ of PBS containing $50 \mathrm{mg} / \mathrm{L}$ Neutral Red (Sigma Aldrich, Zwijndrecht, The Netherlands), and rinsed with fixative containing $0.5 \% \mathrm{v} / \mathrm{v}$ formaldehyde and $1 \% \mathrm{w} / \mathrm{v} \mathrm{CaCl}_{2}$ in MilliPore water. This was followed by a 10-min incubation in a $400 \mu \mathrm{L}$ solution of $50 \%(\mathrm{v} /$ v) absolute ethanol, $49 \%$ Millipore water, and $1 \%(\mathrm{v} / \mathrm{v})$ glacial acetic acid. Neutral Red fluorescence was measured at 530/645 nm.

The EROD assay was performed on the RTL-W1 cells to assess cytochrome P450 1A activity induced by benzo(a)pyrene. The assay procedure is described in Ganassin et al. (33) and Bols et al. (35). Briefly, after a washing step with PBS, cells were exposed to 400 $\mu \mathrm{L}$ of Dulbecco's modified Eagle's medium (DMEM) without phenol red and with $0.825 \mu \mathrm{M}$ of 7-ethoxyresorufin (Invitrogen, Breda, The Netherlands). The fluorescent product, resorufin, was measured every $3 \mathrm{~min}$ for $30 \mathrm{~min}$ at 530/595 $\mathrm{nm}$. Standard curves of resorufin (Sigma Aldrich, Zwijdrecht, The Netherlands) were generated to convert fluorescence units to picomoles of resorufin. To express EROD activity in terms of pmol resorufin $/ \mathrm{min} / \mathrm{mg}$ protein, the amount of cell protein on each insert was determined using the Fluorescamine assay. The cells were rinsed with fixative and then frozen for $1 \mathrm{~h}$ in $100 \mu \mathrm{L}$ of Millipore water at $-80{ }^{\circ} \mathrm{C}$. They were then incubated for $5 \mathrm{~min}$ in an additional $200 \mu \mathrm{L}$ of PBS and $100 \mu \mathrm{L}$ of acetone with $0.3 \mathrm{~g} / \mathrm{L}$ fluorescamine (Sigma Aldrich, Zwijndrecht, The Netherlands). Fluorescamine fluorescence was measured at 360/460 nm. Protein standard curves were generated using bovine serum albumin (BSA, 98\% purity, essentially fatty-acid and $\gamma$-globulin free, Sigma, St. Louis, MO) in Millipore water.

Chemical Analysis. Analyses determining benzo( $a$ )pyrene concentrations in the medium and PDMS were performed using HPLC with fluorescence detection. The HPLC system was equipped with a Shimadzu DGU 14A degasser (Den Bosch, The Netherlands), a Varian 9012 pump, a Merck Hitachi F-1050 fluorescence spectrophotometer (Maarssen, The Netherlands), and a C18 Supelcosil LCPAH column $(150 \mathrm{~mm} \times 4.6 \mathrm{~mm}$ i.d. $\times 5 \mu \mathrm{m}$, Supelco, Bellefonte, PA) that was operated at $40{ }^{\circ} \mathrm{C}$. All analyses were performed at a flow rate of $1000 \mu \mathrm{L} /$ minute using 95/5\% methanol/water as an eluent and an injection volume of $20 \mu \mathrm{L}$. The excitation and emission wavelengths were set at 264/308 nm. Chromatograms were checked by hand after automatic integration (Chromcard v. 2.3.3 software, Thermo Electron Corporation, Rodano, Italy).

The concentrations of chlorobenzenes in medium and PDMS extracts were determined by gas chromatography with electron capture detection (GC-ECD). The system consisted of a Trace GC Ultra gas chromatograph (Thermo Electron Scientific, Rodano, Italy) equipped with a split injector, a Triplus autosampler, and an electron capture detector. One microliter of cyclohexane extract was injected at $175^{\circ} \mathrm{C}$ in split mode (split factor 25 ) on a deactivated uncoated precolumn $(1.5 \mathrm{~m} \times 0.53 \mathrm{~mm})$ connected to a fused-silica Restek Rxi-5SIL MS separation column of $30 \mathrm{~m} \times 0.25 \mathrm{~mm}$ with a coating thickness of $0.25 \mu \mathrm{m}$ (Restek U.S. Bellefonte, PA). Helium (1.5 $\mathrm{mL} / \mathrm{min}$ at constant flow) was used as a carrier gas. The column was kept at $160{ }^{\circ} \mathrm{C}$. The GC-ECD performance was tested every 10 samples by injecting an external standard solution. Chromatograms were checked by hand after automatic integration (Chromcard v. 2.3.3 software, Thermo Scientific, Rodano, Italy).

Data Analysis. Sigmoidal dose-response curves were constructed using the $\log -$ logistic distribution model with a variable slope. They were constructed as a function of log concentrations of the test chemical against the percentage of fluorescence of the control (blank PDMS or DMSO) in the case of cell viability and against the absolute enzyme activity in the case of EROD induction. Dose-response curves obtained from in vitro EROD assays typically have a maximum EROD response at a given chemical concentration and a drop afterward due to nonarylhydrocarbon receptor mediated mechanisms (36). Dose-response curves through EROD assay data were constructed by excluding the negativesloping portion of the curve in the fit. Statistical differences among treatments were determined by a two-tailed Student's $t$ test, with a significance level set at $>95 \%(p<0.05)$. All error propagations, statistical analyses, and fits were done using GraphPad Prism 4.0 (GraphPad Software Inc., San Diego, CA).

\section{Results and Discussion}

Loading PDMS in Methanol/Water Loading-Solution. The mass balance of the loading system consisting of PDMS sheets in the methanol/water mixture was $\geq 95 \%$ for all compounds tested. The mass balance of the system was determined by comparing the total amount of the test chemical in the loadingsolution and PDMS disks after loading to the initial amount measured in the loading-solution. The maximum loaded concentrations in PDMS and the $\log K_{\text {PDMS/loading-solution of ben- }}$ zo(a)pyrene, 1,2-dichlorobenzene, and 1,2,4-trichlorobenzene are given in Table 1 . The $\log K_{\mathrm{PDMS} / \text { loading-solution values are in }}$ the same range as the partition coefficients measured in methanol/water mixtures ( $\mathrm{v} / \mathrm{v}$ of $0.5 / 0.5$ ) reported by Ter Laak et al. (37). The measured coefficients were used to estimate the concentrations needed in the loading-solution to obtain the concentrations in PDMS required to differentially dose cell assays with benzo(a)pyrene, 1,2-dichlorobenzene, and 1,2,4trichlorobenzene.

PDMS Depletion Kinetics. The depletion kinetics of the loaded PDMS disks exposed to the culture medium that contained 5\% FBS in the RTgill-W1 cytotoxicity assay are shown in Figure 2. Equations 2 and 3 were used to fit the kinetics data. An equilibration period of $24 \mathrm{~h}$ was sufficient to reach equilibrium for all compounds tested. The desorption rate constants, $k_{\mathrm{d}}$, are listed in Table 1 . Like in Kwon et al. (30), the time to equilibrium was found to be dependent on the $K_{\mathrm{OW}}$ of the chemical. 1,2-Dichlorobenzene, the least hydrophobic chemical $\left(\log K_{\text {OW }} 3.43(38)\right.$ ), had a $k_{\mathrm{d}}( \pm \mathrm{SE})$ of $5.94 \pm 0.80$ $\times 10^{-4} \mathrm{~s}^{-1}$, and equilibrium was reached after $2 \mathrm{~h}$. Benzo $(a)$ pyrene, the most hydrophobic chemical $\left(\log K_{\text {OW }} 6.22\right.$ (39)), had 
Table 1. Concentrations and Partition Coefficients of 1,2-Dichlorobenzene, 1,2,4-Trichlorobenzene, and Benzo(a)pyrene in Two Fish Cell Assays Using Conventionally Dosed and Partition-Controlled Dosing Systems ${ }^{a}$

\begin{tabular}{|c|c|c|c|}
\hline test chemical & 1,2-dichlorobenzene & 1,2,4-trichlorobenzene & benzo $(a)$ pyrene \\
\hline assay & basal cytotoxicity assay with RTgill-W1 & basal cytotoxicity assay with RTgill-W1 & EROD assay with RTL-W1 \\
\hline $\log K_{\mathrm{OW}}$ & $3.43^{b}$ & $4.05^{b}$ & $6.13^{c}$ \\
\hline Henry's law constant $\left(\mathrm{Pa} \mathrm{m}^{3} / \mathrm{mol}\right)$ & $195^{d}$ & $101^{d}$ & $0,034^{c}$ \\
\hline$K_{\text {PDMS/loading-solution }}$ & $12.43 \pm 1.13$ & $26.31 \pm 3.02$ & $85.38 \pm 4.64$ \\
\hline $\begin{array}{l}\text { maximum concentration loaded } \\
\text { into PDMS }(\mathrm{g} / \mathrm{L}) \pm \mathrm{SD}\end{array}$ & $150.58 \pm 7.86$ & $264.93 \pm 25.65$ & $0.31 \pm 0.008$ \\
\hline$k_{\mathrm{d}}\left(\times 10^{-4} \mathrm{~s}^{-1}\right) \pm \mathrm{SE}$ & $5.94 \pm 0.80$ & $5.03 \pm 0.92$ & $3.90 \pm 0.10$ \\
\hline \multicolumn{4}{|l|}{$\log K_{\mathrm{PDMS} / \mathrm{L} 15 \text { serum }} \pm \mathrm{SE}$} \\
\hline lowest tested medium concentration & $3.29 \pm 0.02$ & $3.60 \pm 0.08$ & $2.28 \pm 0.02$ \\
\hline highest tested medium concentration & $3.54 \pm 0.04$ & $3.83 \pm 0.05$ & $2.39 \pm 0.01$ \\
\hline \multicolumn{4}{|l|}{$\begin{array}{l}\text { chemical recovered from medium } \\
\text { exposed } 48 \mathrm{~h}(\%)\end{array}$} \\
\hline conventional dosing system & $5 \pm 3 \%$ & $11 \pm 2 \%$ & $64 \pm 5 \%$ \\
\hline partition-controlled dosing system & $109 \pm 18 \%$ & $105 \pm 10 \%$ & $95 \pm 3 \%$ \\
\hline $\begin{array}{l}\text { chemical bound to serum } \\
\text { constituents }(\%)\end{array}$ & $61 \%$ & $70 \%$ & $99.8 \%$ \\
\hline
\end{tabular}

${ }^{a} \log K_{\mathrm{PDMS} / \mathrm{L} 15 \text { serum }} \pm \mathrm{SE}$ are taken from the experiments depicted in Figures 3-4. ${ }^{b}$ From De Bruijn et al. (38). ${ }^{c}$ From De Maagd et al. (39). ${ }^{d}$ From Shiu and Mackay (43).

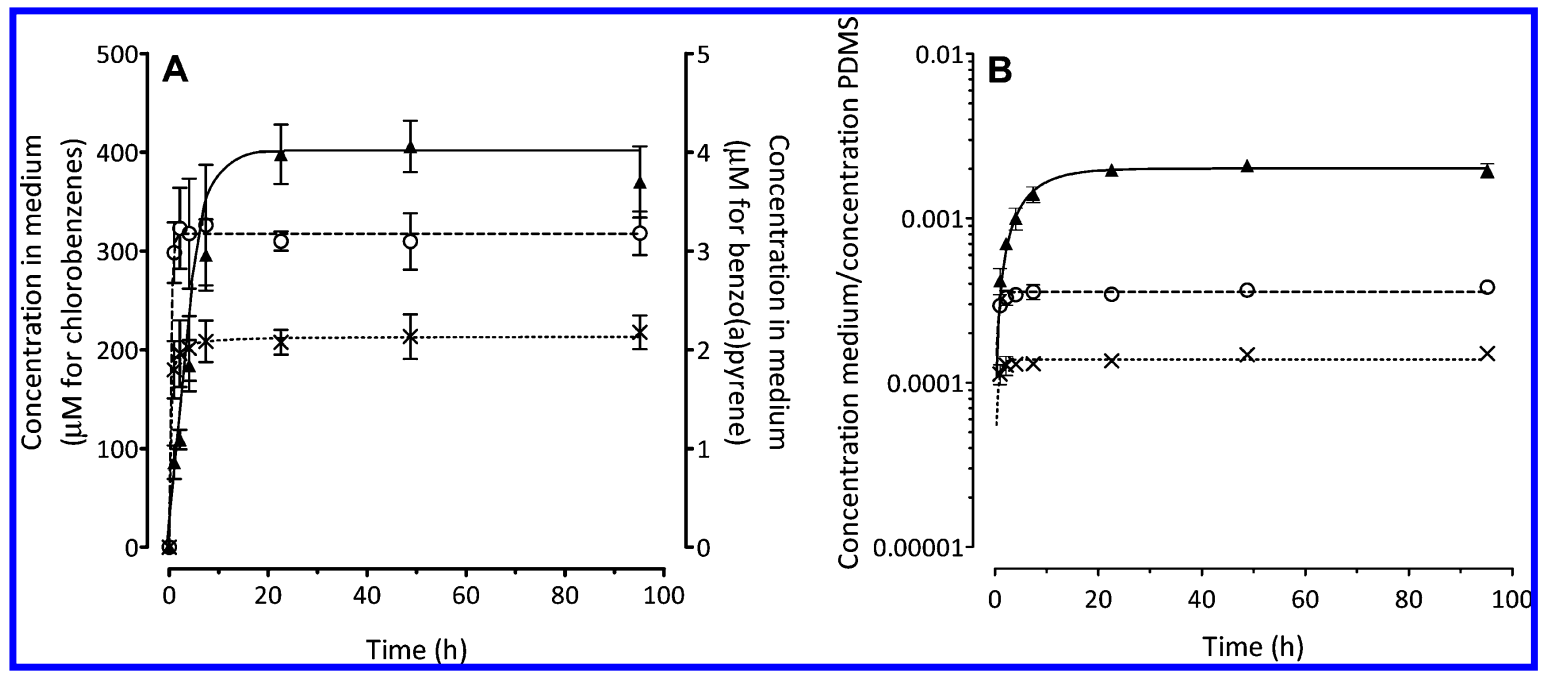

Figure 2. Change in concentrations in medium containing 5\% FBS (A) and change in the ratio of medium concentration and PDMS concentration $(B)$ of benzo(a)pyrene $(\mathbf{\Lambda})$, 1,2-dichlorobenzene $(\times)$, and 1,2,4-trichlorobenzene $(O)$ in a partition-controlled dosing system. Data are fit to eqs 2 and 3 to determine $k_{\mathrm{d}}$, the desorption rate constant. $R^{2}$ was $\geq 0.88$.

a $k_{\mathrm{d}}( \pm \mathrm{SE})$ of $3.90 \pm 0.10 \times 10^{-4} \mathrm{~s}^{-1}$, and equilibrium was reached after $20 \mathrm{~h}$. Typical cell assays run for 24 to $48 \mathrm{~h}$, which would be enough time for even very hydrophobic chemicals such as benzo $(a)$ pyrene to reach equilibrium in the partitioncontrolled dosing system described in this study.

Stability and Predictability of Nominal and Free Medium Concentrations. Figure 2 also illustrates that total medium concentrations of all test chemicals remain constant for at least $72 \mathrm{~h}$ after equilibration. This suggests that whatever fraction of the test chemical is lost from the system over time, PDMS sufficiently compensates for the loss. Indeed, the depleted fraction of test chemical in PDMS was small to negligible. The fraction $( \pm \mathrm{SD})$ of test chemical left in PDMS after $96 \mathrm{~h}$ of exposure to the cell system, as compared to before exposure, was $\geq 90 \%$.

Log $K_{\mathrm{PDMS} / \mathrm{L} 15 \text { serum }}$ increased with increasing concentrations of benzo(a)pyrene, 1,2-dichlorobenzene, and 1,2,4-trichlorbenzene in the culture medium. The measured $\log K_{\mathrm{PDMS} / \mathrm{L} 15 \mathrm{serum}}$ values at the lowest tested concentrations in medium are significantly lower than the $\log K_{\mathrm{PDMS} / \mathrm{L} 15 \text { serum }}$ values at the highest tested concentrations in the medium of all three test compounds ( $p<0.05$ in two-tailed Student's $t$ test, Table 1). The saturation of serum protein binding at high concentrations of a test chemical in culture medium (i.e., near maximum solubility) may explain the difference in $K_{\mathrm{PDMS} / \mathrm{L} 15 \text { serum }}$ at high and low concentrations in the culture medium.

Table 1 also lists the $\log K_{\mathrm{PDMS} / \mathrm{L} 15}$ for all three chemicals tested. These partition coefficients are similar to PDMS-water partition coefficients and increase with increasing $\log K_{\mathrm{OW}}$, as is congruent with the literature listing PDMS-water partition coefficients for these chemicals $(37,40)$. We therefore assume that there are no major binding elements in the bare culture medium (L-15). Moreover, the relationship between $\log K_{\mathrm{OW}}$ and PDMS - water partition coefficients may be used to estimate $K_{\mathrm{PDMS} / \mathrm{L} 15}$ for similar chemicals. For all three chemicals tested, $\log K_{\mathrm{PDMS} / \mathrm{L} 15}$ was higher than $\log K_{\mathrm{PDMS} / \mathrm{L} 15 \text { serum }}$ at the lowest tested concentration (assuming that at this concentration no saturation of serum binding constituents occurred). This indicates that all chemicals bind to serum constituents. Using eq 6 and the measured total medium concentrations, it was calculated that 61,70 , and $99.8 \%$ of 1,2-dichlorobenzene, 1,2,4-trichlorobenzene, and benzo $(a)$ pyrene in the culture medium are bound to serum constituents at the lowest tested concentrations, respectively. The extent of binding increases with increasing $\log K_{\mathrm{OW}}$ of the chemical, which is consistent with the findings of DeBruyn and Gobas (41). 


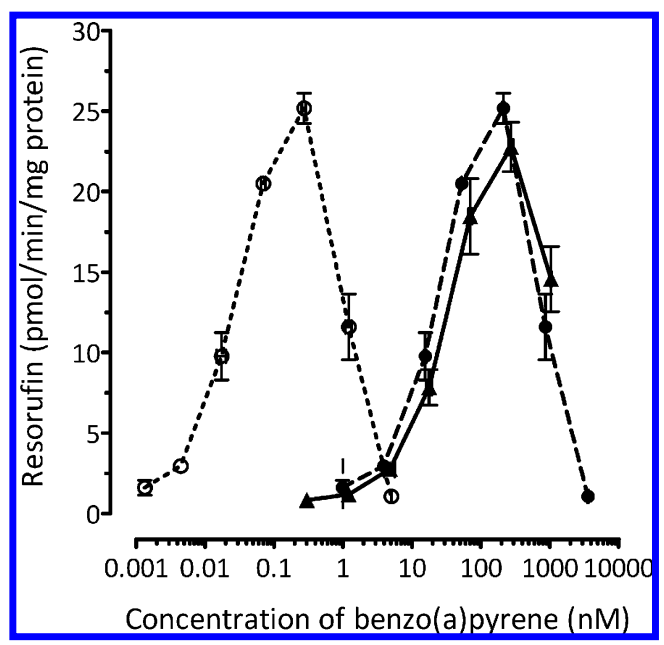

Figure 3. EROD activity in pmol resorufin/min/mg protein $( \pm \mathrm{SD}$, one experiment) of RTL-W1 exposed for $48 \mathrm{~h}$ to benzo $(a)$ pyrene (analytically measured medium concentrations at the start of the exposure period in $\mathrm{nM} \pm \mathrm{SD}$ ). Data from the partition-controlled dosing system are based on either measured total $(\mathbf{0})$ or estimated free concentrations $(\bigcirc)$. Data from the conventionally dosed assay, based on total measured concentrations at the start of exposure, are indicated by triangles. All replicate experiments resulted in similar shifts in dose-response curves.

EROD Activity of Benzo(a)pyrene. Benzo $(a)$ pyrene significantly induced EROD activity in RTL-W1, with a maximum rate of resorufin production $( \pm \mathrm{SE})$ of $25.97 \pm 0.17 \mathrm{pmol}$ resorufin/min/mg cell protein (Figure 3 ). Conventional dosing of benzo(a)pyrene resulted in a median effect concentration $\left(\mathrm{EC}_{50} \pm \mathrm{SE}\right.$ from one experiment, based on total measured medium concentrations at the start of the experiment) of 31.37 $\pm 1.05 \mathrm{nM}$ (Table 2). Both the maximum level of EROD induction and the $\mathrm{EC}_{50}$ are similar to those reported in Bols et al. (35) and Schirmer et al. (42). The percentage $( \pm \mathrm{SD})$ of benzo(a)pyrene recovered from the medium after the 48-h exposure period was $64 \pm 5 \%$ (Table 1).

For the assay dosed via the partition-controlled dosing system, the concentration of benzo $(a)$ pyrene in the culture medium at the end of the 48-h exposure was measured to be $95 \pm 3 \%$ ( \pm SD from one experiment) of the concentration before the addition of the cells. This illustrates the system's effectiveness at maintaining medium concentrations of hydrophobic and metabolized chemicals constant (Table 1). The $\mathrm{EC}_{50}( \pm \mathrm{SE}$ from one experiment, based on measured total concentrations at the start of the experiment) in the partition-controlled dosing system was $23.95 \pm 1.02 \mathrm{nM}$, slightly lower than the $\mathrm{EC}_{50}$ obtained by conventional dosing (ANOVA $\mathrm{F}(21.24(1,3)), p=0.03$;
Figure 3 and Table 2). The $\mathrm{EC}_{50}( \pm \mathrm{SE})$ based on free concentrations of benzo $(a)$ pyrene was $0.0284 \pm 0.0003 \mathrm{nM}$ (Table 2). Results also indicated that PDMS itself was not toxic and did not induce EROD activity in RTL-W1.

The $\sim 30 \%$ difference between the fractions of benzo $(a)$ pyrene recovered from the medium after $48 \mathrm{~h}$ of exposure to cells in the PDMS- and conventionally dosed systems may explain the $\sim 25 \%$ difference in nominal effect concentrations. However, it should be noted that the $\mathrm{EC}_{50}$ in PDMS-dosed systems in three separate experiments varied between 20 to $35 \mathrm{nM}$, and that the difference between PDMS- and conventionally dosed effect concentrations was generally only slightly significant. The total concentration of benzo $(a)$ pyrene in the culture medium in a conventionally dosed assay stays relatively constant over the exposure period (i.e., does not decrease strongly by, for example, metabolism, evaporation, or plastic binding). Any difference in $\mathrm{EC}_{50}$ between the conventionally dosed assay and PDMS-dosed assay due to differences in total concentrations after exposure may, therefore, be masked by the general variation in assay results.

Cytotoxicity of Chlorobenzenes. Figure 4 depicts the dose-response curves for 1,2-dichlorobenzene and 1,2,4trichlorobenzene in both the conventionally dosed and the PDMS-dosed RTgill-W1 CFDA-AM assay. The $\mathrm{EC}_{50}$ values for the CFDA-AM assay and the percentage of chlorobenzene recovered from the medium (i.e., the quotient of the total concentration in medium measured after and before exposure to the cells) are given in Tables 1 and 2 . The $\mathrm{EC}_{50}$ values from all three cytotoxicity assays performed (i.e., Alamar Blue, CFDA-AM, and Neutral Red) are given in the Supporting Information (Table S1 and Figure S1). Alamar Blue is for both chlorobenzenes the most sensitive assay of the three assays tested, but the differences in $\mathrm{EC}_{50}$ values are small. The cytotoxicity values for 1,2-dichlorobenzene from the conventionally dosed assays are within the ranges reported for the chemical in Tanneberger et al. (5) (see indirect dosing method).

The concentration of 1,2-dichlorobenzene and 1,2,4-trichlorobenzene in the culture medium at the end of the 48-h exposure was measured to be $109 \pm 18 \%$ and $105 \pm 10 \%$ of the concentration before the addition of the cells (Table 1). These results illustrate the system's effectiveness in maintaining constant medium concentrations of volatile chemicals. In stark contrast to the recoveries from the partition-controlled dosing system, chlorobenzene concentrations in medium after $48 \mathrm{~h}$ of exposure to cells in the conventionally dosed assays were a tenth or less of the original concentrations added (Table 1). The majority of the chemical is assumed to have evaporated out of the medium over the test period. The loss of 1,2-dichlorobenzene

Table 2. EC $_{50}$ Values of 1,2-Dichlorobenzene, 1,2,4-Trichlorobenzene, and Benzo(a)pyrene in Two Fish Cell CFDA-AM Assays Using Conventionally Dosed and Partition-Controlled Dosing Systems ${ }^{a}$

\begin{tabular}{|c|c|c|c|}
\hline test chemical & 1,2-dichlorobenzene & 1,2,4-richlorobenzene & benzo $(a)$ pyrene \\
\hline assay & $\begin{array}{l}\text { basal cytotoxicity assay with } \\
\text { RTgill-W1 }\end{array}$ & $\begin{array}{l}\text { basal cytotoxicity assay with } \\
\text { RTgill-W1 }\end{array}$ & EROD assay with RTL-W1 \\
\hline $\begin{array}{l}\mathrm{EC}_{50}(\mu \mathrm{M}) \pm \mathrm{SE} \\
\text { conventional dosing, based on } \\
\text { measured total medium } \\
\text { concentrations at start of exposure }\end{array}$ & $609.32 \pm 4.31$ & $135.40 \pm 1.07$ & $31.37 \times 10^{-3} \pm 1.05 \times 10^{-3}$ \\
\hline $\begin{array}{l}\text { partition-controlled dosing, based on } \\
\text { total medium concentrations at start } \\
\text { of exposure }\end{array}$ & $94.93 \pm 2.20$ & $37.60 \pm 1.07$ & $23.95 \times 10^{-3} \pm 1.02 \times 10^{-3}$ \\
\hline acute $\mathrm{LC}_{50}$ fat head minnow $(\mu \mathrm{M})^{b}$ & 64 & 16 & $\mathrm{n} / \mathrm{a}$ \\
\hline
\end{tabular}




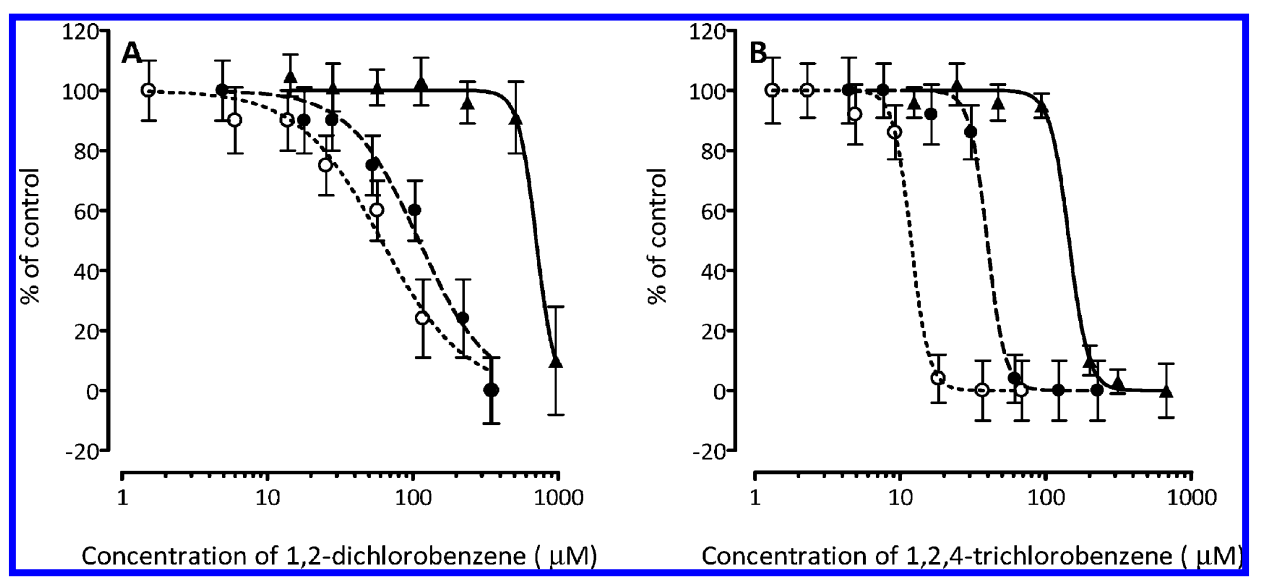

Figure 4. Viability, as measured using in the CFDA-AM assay and expressed as a percentage of control ( \pm SD, one experiment), of RTgill-W1 exposed for $48 \mathrm{~h}$ to 1,2-dichlorobenzene (A) and 1,2,4-trichlorobenzene (B) $\left(R^{2} \geq 0.96\right)$. Analytically measured medium concentrations at the start of the exposure $(\mu \mathrm{M} \pm \mathrm{SD})$ have been used. Data from the partition-controlled dosing system are based on either measured total $(\mathbf{0})$ or estimated free concentrations $(\bigcirc)$. Data from the conventionally dosed assay, based on measured total medium concentrations, are indicated by triangles. All replicate experiments gave similar results.

was greater than for 1,2,4-trichlorobenzene presumably because 1,2-dichlorobenzene has a higher Henry's law constant (i.e., will partition more from aqueous phase to the gas phase because it is more volatile despite its slightly higher water solubility) than 1,2,4-trichlorobenzene (Table 1 (43)).

The $\mathrm{EC}_{50}$ values, based on measured total medium concentrations, obtained using the partition-controlled dosing assay resemble reported median acutely lethal concentrations, $\mathrm{LC}_{50}$ values, for fathead minnow more closely than $\mathrm{EC}_{50}$ values obtained using the conventionally dosed assay (Table $2(44,45)$ ). The $\mathrm{EC}_{50}$ values based on estimated free concentrations are even closer to the reported median lethal concentrations for fathead minnow than the $\mathrm{EC}_{50}$ values based on measured total medium concentrations obtained via the PDMS-dosing system (Table 2 ). For both chlorobenzenes, the $\mathrm{EC}_{50}$ values obtained using conventional dosing are five to seven times higher than the $\mathrm{EC}_{50}$ values obtained using PDMS dosing. This can partly be explained by the 10 to 20 times lower medium concentrations after exposure. The fraction of test chemical in medium after $48 \mathrm{~h}$ of exposure, however, does not necessarily fully explain the observed cytotoxicity as toxicity is a function of medium concentrations over the entire exposure period. The conventionally dosed medium concentrations are similar to PDMS-dosed medium concentrations at the start of the exposure and presumably only gradually decrease to less than a tenth of the original concentrations due to continuous evaporation.

Implications and Relevance. This study addresses the need to improve dosing techniques in cell assays for volatile test chemicals. It reports that more than $90 \%$ of volatile test chemicals such as 1,2-dichlorobenzene and 1,2,4-trichlorobenzene are lost over a 48-h exposure period, drastically reducing the apparent toxicity in a RTgill-W1 cytotoxicity assay. Indeed, the evaporation of volatile chemicals may explain the low absolute sensitivity of cell assays to quantitatively predict the acute toxicity of volatile chemicals to fish $(4,46)$. The partitioncontrolled dosing system developed in this study can compensate for the loss through evaporation of chlorobenzenes from microtiter plates and keep the concentration of these chemicals constant in culture medium.

This study also addresses the need to use free instead of nominal concentrations of hydrophobic chemicals in culture medium to construct dose-response curves. Because the free concentration can be regarded as the bioavailable concentration in a cellular assay, the free concentration is an important entity in interpreting in vitro toxicity data $(14,46)$. What is striking is that the free concentration of the hydrophobic chemical, benzo $(a)$ pyrene, is a very small fraction of the nominal concentration. The chemical strongly binds to serum components in culture medium. The partition-controlled dosing system described in this study allows for the determination of the free concentration of hydrophobic chemicals like benzo $(a)$ pyrene if the concentration of the chemical in PDMS and the partition coefficient of the chemical to PDMS from the bare culture medium $\left(K_{\mathrm{PDMS} / \mathrm{L} 15}\right)$ are known (eq 6). Thus, dosing and determining free concentrations are performed simultaneously. The strength of this approach has also been shown by Smith et al. (26).

A number of criteria for a successful in vitro partitioncontrolled dosing system were met in this study (19). After equilibration, the test chemical remained constant for at least $72 \mathrm{~h}$. Equilibration generally occurred within $24 \mathrm{~h}$ and thus within the test assay exposure duration. The need for stirring was circumvented to avoid damage to the fish cells $(19,27)$. The reservoir of a test chemical in PDMS was large enough to compensate for the loss of $95 \%$ of a test chemical in medium. PDMS disks were loaded with a wide and predictable range of test chemical concentrations via a spiked methanol/water loading-solution. Lastly, the cells were uniformly exposed to chemicals without touching the dosing surface $(24,26)$. By growing the cells on the bottom of culture plate inserts, the cells were equidistant from the PDMS disks $(\sim 1 \mathrm{~mm})$. The use of culture plate inserts and loose PDMS disks generally gave enough flexibility to perform a suite of assays on the same group of cells. PDMS itself did not interfere with the biological activity of cells.

As mentioned in the Introduction, several partition-controlled dosing systems have been applied to bioassays (18, 19, 22-29). The strengths of the system described in this study, in comparison to earlier systems, are that it is applicable to cell based assays performed in microtiter plates, that it is relatively simple to apply, that it is possible to estimate free concentrations, that the cells are uniformly exposed, that there is no direct contact between cells and the solid phase, and that no stirring regime was needed. Moreover, the focus in this study has been on fish cell assays, but the dosing technique can, theoretically, be applied to other cell assays. However, there are a number of issues that still need to be addressed before this partitioncontrolled dosing system can be applied to other cell assays with other test chemicals. This study only used relatively nonpolar, simple organic chemicals with a strong affinity for 
PDMS. Future research will need to verify whether this in vitro dosing system functions well with more complex chemicals (e.g., large, polar, or charged chemicals).

Acknowledgment. This work was financially supported by CEllSens, a CEFIC-LRI/DEFRA-UK research grant, ACuteTox, an EU-FP6 Integrated Project (EU LSHD CT 2004-512051), and the SETAC Procter and Gamble Fellowship (2007). We thank Katrin Tanneberger for introducing the cell assays and critically reviewing the manuscript and Jolanda van den Brink for her help culturing the cells. We also thank Thomas Wüthrich and Jung-Hwan Kwon for introducing the PDMS loading methods.

Supporting Information Available: $\mathrm{EC}_{50}$ values and full dose-response curves for 1,2-dichlorobenzene and 1,2,4trichlorobenzene using three cytotoxicity assays. This material is available free of charge via the Internet at http://pubs.acs.org.

\section{References}

(1) Castaño, A., Bols, N. C., Braunbeck, T., Dierick, P., Halder, M., Isomaa, B., Kawahara, K., Lee, L. E. J., Mothersill, C., Pärt, P., Repetto, G., Sintes, J. R., Rufli, H., Smith, R., Wood, C., and Segner, H. (2003) The use of fish cells in ecotoxicology. The report and recommendations of ECVAM workshop 47. ATLA 31, 317-351.

(2) Bols, N. C., Dayeh, V. R., Lee, L. E. J., and Schirmer, K. (2005) Use of Fish Cell Lines in the Toxicology and Ecotoxicology of Fish, in Biochemistry and Molecular Biology of Fishes (Mohn, T. W., and Mommsen, T. P., Eds.) Vol. 6, Chapter 2, Elsevier Science, Amsterdam, The Netherlands.

(3) Schirmer, K. (2006) Proposal to improve vertebrate cell cultures to establish them as substitutes for the regulatory testing of chemicals and effluents using fish. Toxicology 224, 163-183.

(4) Kramer, N. I., Hermens, J. L. M., and Schirmer, K. (2009) The influence of modes of action and physicochemical properties of chemicals on the correlation between in vitro and acute fish toxicity data. Toxicol. in Vitro 23, 1372-1379.

(5) Tanneberger, K., Rico-Rico, Á., Kramer, N. I., Busser, F. J. M. Hermens, J. L. M., and Schirmer, K. (2010) Effects of solvents and dosing procedure on chemical toxicity in cell-based in vitro assays. Environ. Sci. Technol. 44, 4775-4781.

(6) Riedl, J., and Altenburger, R. (2007) Physicochemical substance properties as indicators for unreliable exposure in microplate-based bioassays. Chemosphere 67, 2210-2220.

(7) Schreiber, R., Altenburger, R., Paschke, A., and Küster, E. (2008) How to deal with lipophilic and volatile organic substances in microtiter plate assays. Environ. Toxicol. Chem. 27, 1676-1682.

(8) Schirmer, K., Chan, A. G. J., Greenberg, B. M., Dixon, D. G., and Bols, N. C. (1997) Methodology for demonstrating and measuring the photocytotoxicity of fluoranthene to fish cells in culture. Toxicol. in Vitro 11,107-119.

(9) Gellert, G., and Stommel, A. (1999) Influence of microplate material on the sensitivity of growth inhibition tests with bacteria assessing toxic organic substances in water and waste water. Environ. Toxicol. $14,424-428$

(10) Gülden, M., Mörchel, S., and Seibert, H. (2001) Factors influencing nominal effective concentrations of chemical compounds in vitro: Cell concentration. Toxicol. in Vitro 15, 233-243.

(11) Gülden, M., Mörchel, S., Tahan, S., and Seibert, H. (2002) Impact of protein binding on the availability and cytotoxic potency of organochlorine pesticides and chlorophenols in vitro. Toxicology 175, 201213.

(12) Hestermann, E. V., Stegeman, J. J., and Hahn, M. E. (2000) Serum alters the uptake and relative potencies of halogenated aromatic hydrocarbons in cell culture bioassays. Toxicol. Sci. 53, 316-325.

(13) Seibert, H., Mörchel, S., and Gülden, M. (2002) Factors influencing nominal effective concentrations of chemical compounds in vitro, Medium protein concentration. Toxicol. in Vitro 16, 289-297.

(14) Heringa, M. B., Schreurs, R. H. M. M., Busser, F., Van Der Saag, P. T., Van Der Burg, B., and Hermens, J. L. M. (2004) Toward more useful in vitro toxicity data with measured free concentrations. Environ. Sci. Technol. 38, 6263-6270.

(15) Calleja, M. C., and Persoone, G. (1993) The influence of solvents on the acute toxicity of some lipophilic chemicals to aquatic invertebrates. Chemosphere 26, 2007-2022.

(16) Fadnavis, N. W., Seshadri, R., Sheelu, G., and Madhuri, K. V. (2005) Relevance of Frank's solvent classification as typically aqueous and typically non-aqueous to activities of firefly luciferase, alcohol dehydrogenase, and $\alpha$-chymotrypsin in aqueous binaries. Arch. Biochem. Biophys. 433, 454-465.

(17) Hutchinson, T. H., Shillabeer, N., Winter, M. J., and Pickford, D. B. (2006) Acute and chronic effects of carrier solvents in aquatic organisms, A critical review. Aquat. Toxicol. 76, 69-92.

(18) Brown, R. S., Akhtar, P., Akerman, J., Hampel, L., Kozin, I. S., Villerius, L. A., and Klamer, H. J. C. (2001) Partition controlled delivery of hydrophobic substances in toxicity tests using poly(dimethylsiloxane) (PDMS) films. Environ. Sci. Technol. 35, 4097-4102.

(19) Gerofke, A., Kömp, P., and McLachlan, M. S. (2004) Stir bar contamination, A method to establish and maintain constant water concentrations of poorly water-soluble chemicals in bioconcentration experiments. Water Res. 38, 3411-3419.

(20) OECD (1992) Guidelines for Testing of Chemicals. Effects on Biotic Systems. Method 203. Fish, Acute Toxicity Test. Adopted July 17, 1992, Organisation for Economic Cooperation and Development, Paris, France.

(21) OECD (1996) Guideline No. 305. Bioconcentration: Flow-through Fish Test, Organisation for Economic Cooperation and Development, Paris, France.

(22) Mayer, P., Wernsing, J., Tolls, J., De Maagd, P. G. J., and Sijm, D. T. H. M. (1999) Establishing and controlling dissolved concentrations of hydrophobic organics by partitioning from a solid phase. Environ. Sci. Technol. 33, 2284-2290.

(23) Janz, S., and Shacter, E. (1991) A new method for delivering alkanes to mammalian cells: Preparation and preliminary characterization of an inclusion complex between $\beta$-cyclodextrin and pristane $(2,6,10,14-$ tetramethylpentadecane). Toxicology 69, 301-315.

(24) Bopp, S. K., Bols, N. C., and Schirmer, K. (2006) Development of a solvent-free, solid-phase in vitro bioassay using vertebrate cells. Environ. Toxicol. Chem. 25, 1390-1398.

(25) Heinis, L. J., Highland, T. L., and Mount, D. R. (2004) Method for testing the aquatic toxicity of sediment extracts for use in identifying organic toxicants in sediments. Environ. Sci. Technol. 38, 6256-6262.

(26) Smith, K. E. C., Oostingh, G. J., and Mayer, P. (2010) Passive dosing for producing defined and constant exposure of hydrophobic organic compounds during in vitro toxicity tests. Chem. Res. Toxicol. $23,55-$ 65.

(27) Bandow, N., Altenburger, R., Lubcke-Von Varel, U., Paschke, A., Streck, G., and Brack, W. (2009) Partitioning-based dosing: An approach to include bioavailability in the effect-directed analysis of contaminated sediment samples. Environ. Sci. Technol. 43, 3891-3896.

(28) Bandow, N., Altenburger, R., Streck, G., and Brack, W. (2009) Effectdirected analysis of contaminated sediments with partition-based dosing using green algae cell multiplication inhibition. Environ. Sci. Technol. 43, 7343-7349.

(29) Kiparissis, Y., Akhtar, P., Hodson, P. V., and Brown, R. S. (2003) Partition-controlled dosing of toxicants: A novel in vivo approach for embryo toxicity testing. Environ. Sci. Technol. 37, 2262-2266.

(30) Kwon, J. H., Wuethrich, T., Mayer, P., and Escher, B. I. (2009) Development of a dynamic delivery method for in vitro bioassays. Chemosphere 76, 83-90.

(31) Lee, L. E. J., Clemedson, C., Bechtel, D. G., Caldwell, S. J., Han, K. B., Pasitschniak-Arts, M., Mosser, D. D., and Bols, N. C. (1993) Development and characterization of a rainbow trout liver cell line expressing cytotchrome $\mathrm{P} 450$-dependent monooxygenase activity. $\underline{\text { Cell }}$ Biol. Toxicol. 9, 279-294.

(32) Peters, T., Jr. (1996) All About Albumin: Biochemistry, Genetics, and Medical Applications, Academic Press, San Diego, CA.

(33) Ganassin, R. C., Schirmer, K., and Bols, N. C. (2000) Cell and Tissue Culture, in The Laboratory Fish (Ostrander, G. K., Ed.) pp 631-651, Academic Press, San Diego, CA.

(34) Schirmer, K., Chan, A. G. J., Greenberg, B. M., Dixon, D. G., and Bols, N. C. (1998) Ability of 16 priority PAHs to be photocytotoxic to a cell line from the rainbow trout gill. Toxicology 127, 143-155.

(35) Bols, N. C., Schirmer, K., Joyce, E. M., Dixon, D. G., Greenberg, B. M., and Whyte, J. J. (1999) Ability of polycyclic aromatic hydrocarbons to induce 7-ethoxyresorufin-o-deethylase activity in a trout liver cell line. Ecotoxicol. Environ. Saf. 44, 118-128.

(36) Verhallen, E. Y., Van den Berg, M., and Bosveld, A. T. C. (1997) Interactive effects on the EROD-inducing potency of polyhalogenated aromatic hydrocarbons in the chicken embryo hepatocyte assay. Environ. Toxicol. Chem. 16, 277-282.

(37) Ter Laak, T. L., Durjava, M., Struijs, J., and Hermens, J. L. M. (2005) Solid phase dosing and sampling technique to determine partition coefficients of hydrophobic chemicals in complex matrixes. Environ. Sci. Technol. 39, 3736-3742.

(38) De Bruijn, J., Busser, F., Seinen, W., and Hermens, J. (1989) Determination of octanol/water partition coefficients for hydrophobic organic chemicals with the 'slow-stirring' method. Environ. Toxicol. Chem. 8, 499-512. 
(39) De Maagd, P. G. J., Ten Hulscher, D. T. H. E. M., Van Den Heuvel, H., Opperhuizen, A., and Sijm, D. T. H. M. (1998) Physicochemical properties of polycyclic aromatic hydrocarbons, aqueous solubilities, n-octanol/water partition coefficients, and Henry's law constants. Environ. Toxicol. Chem. 17, 251-257.

(40) Kwon, J. H., Wuethrich, T., Mayer, P., and Escher, B. I. (2007) Dynamic permeation method to determine partition coefficients of highly hydrophobic chemicals between poly(dimethylsiloxane) and water. Anal. Chem. 79, 6816-6822.

(41) DeBruyn, A. M. H., and Gobas, F. A. P. C. (2007) The sorptive capacity of animal protein. Environ. Toxicol. Chem. 26, 18031808.

(42) Schirmer, K., Chan, A. G. J., and Bols, N. C. (2000) Transitory metabolic disruption and cytotoxicity elicited by benzo[a]pyrene in two cell lines from rainbow trout liver. J. Biochem. Mol. Toxicol. 14 , 262-276.
(43) Shiu, W. Y., and Mackay, D. (1997) Henry's law constants of selected aromatic hydrocarbons, alcohols, and ketones. J. Chem. Eng. Data $42,27-30$.

(44) Russom, C. L., Bradbury, S. P., Broderius, S. J., Hammermeister, D. E., and Drummond, R. A. (1997) Predicting modes of toxic action from chemical structure, acute toxicity in the fathead minnow (Pimephales promelas). Environ. Toxicol. Chem. 16, 948-967.

(45) Schirmer, K., Tanneberger, K., Kramer, N. I., Völker, D., Scholz, S., Hafner, C., Lee, L. E. J., Bols, N. C., and Hermens, J. L. M. (2008) Developing a list of reference chemicals for testing alternatives to whole fish toxicity tests. Aquat. Toxicol. 90, 128-137.

(46) Gülden, M., and Seibert, H. (2005) Impact of bioavailability on the correlation between in vitro cytotoxic and in vivo acute fish toxic concentrations of chemicals. Aquat. Toxicol. $72,327-337$.

TX1002595 